\title{
Pharma backs latest attempt at a global health R\&D treaty
}

Philanthropists, drugmakers and governments all agree: the world's poor are in dire need of new drugs for neglected diseases, but there is not enough money available to develop innovative treatments. Now, a promising global treaty looks set to find a solution-and, unlike previous attempts to reach a similar agreement, this one seems to have the backing of most major players involved in the drug development process.

"A global R\&D agreement used to be a crazy idea," says James Love, an advocate for affordable medicines and director of Knowledge Ecology International, a social justice nonprofit based in Washington, DC. "Now it looks more and more inevitable."

The US government is far and away the largest supporter of global health research and development (R\&D). According to an April report from the Sydney-based nonprofit research group Policy Cures and the Washington, DC-based umbrella organization Global Health Technologies Coalition, the US contributes around $45 \%$ of all money spent on neglected diseases and $70 \%$ of all government investment in the area worldwide. Still, that expenditure-around $\$ 1.4$ billion per yearrepresents only around $0.01 \%$ of the country's gross domestic product (GDP), a tiny fraction that policy experts and health economists hope the rest of the 193 member states of the World Health Organization (WHO) will be willing to match.

Delegates discussed this idea at the WHO's annual assembly in Geneva in late May. Such a move, if adopted, would double the amount of government funding spent internationally on global health $\mathrm{R} \& \mathrm{D}$, from around $\$ 3$ billion each year today to more than $\$ 6$ billion annually. The proposed convention, outlined on 15 May by members of the WHO's Consultative Expert Working Group on Research and Development (CEWG), also calls for participating drug companies that are funded through the initiative to share data about early-stage treatments for neglected disease and for countries to pool their contributions into a central WHO fund, rather than allocating donations individually (PLoS Med. 9, e1001219, 2012).

\section{Commitment issues}

Similar treaties were proposed in 2005 and 2009, but both efforts failed to get off the ground after drug companies lobbied hard against proposed patent reforms that could have opened the door to more generics for a wide variety of drugs, even top sellers in the developing world. This time around, however, the proposed treaty would

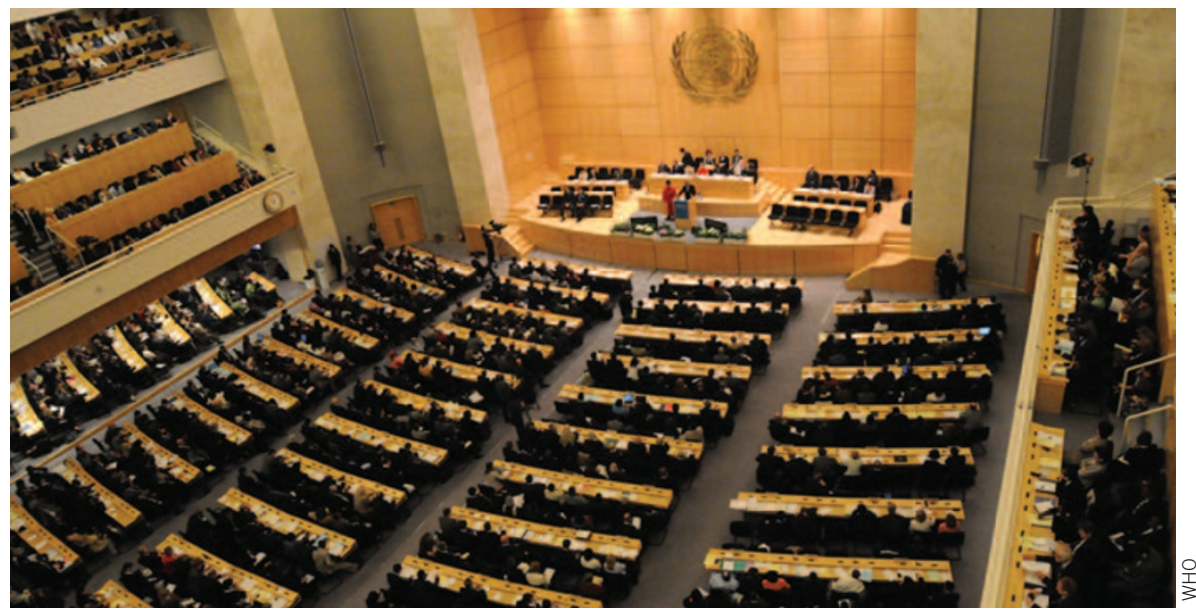

From treaty to treatments: A global accord through the WHO could help.

only loosen patent protection on treatments for diseases largely absent in rich nations, such as malaria, Chagas disease or dengue fever. What's more, the latest proposal includes financial incentives for the pharmaceutical industry, including funding to advance early-stage products for neglected diseases that companies already have in their pipelines.

Importantly, big pharma now seems to back the measure. "Industry is willing to contribute resources to early stage R\&D," says CEWG member Paul Herrling, head of corporate research at the Swiss drug giant Novartis and board chairman of the Singapore-based Novartis Institute for Tropical Diseases. "But to bring those products all the way to the market, they need more than private donors can give."

With pharma largely on board, most global health researchers agree that the main barrier remains persuading the individual member nations to rally around the cause-a difficult task at a time of global austerity measures and belt tightening. "Now we need firm financial commitments from governments," says JohnArne Røttingen, a health economist at the University of Oslo's Institute for Health and Society and chair of the CEWG.

Then comes the challenge of turning talk into action. "We will have to figure out how to build in incentives to make countries comply," says Suerie Moon, a health policy researcher at the Harvard School of Public Health in Boston who coauthored a commentary, also published last month in PLoS Medicine (9, e1001218), in support of the proposed treaty.

The fate of the CEWG's proposal was still unclear as Nature Medicine went to press. But most people involved in the initiative expected the proposal to weather the initial round of discussions at last month's WHO meeting and move toward a committee that will draft formal treaty language based on the CEWG analysis. A full vote could then happen before the end of the year.

Rebecca Hersher

\section{Corrections}

In the March 2012 issue, the article entitled "Korea okays stem cell therapies despite limited peer-review data" (Nat. Med. 18, 329,2012 ), failed to convey that the $26 \%$ improvement in knee function was an additional gain compared to the control group. The sentence should have read: "In an 89-person Korean clinical trial, 26\% more people who received the Medipost treatment experienced an improvement in knee function on a widely used cartilage repair assessment scale compared with those who underwent knee surgery alone." The piece also referred to Francis Han by her Korean name, Han Sung-ho, and did not specify that she is in charge of research and development strategy. The error has been corrected in the HTML and PDF versions of the article. Additionally, as a clarification, the cells referred to as 'banked' in the piece are frozen-stored and do not require donorrecipient matching.

In the May 2012 issue, in the piece "New biologic drugs get under the skin of psoriasis'" (Nat. Med. 18, 638, 2012), sales numbers mistakenly cited for the US psoriasis market were actually sales numbers for the G7 (US, UK, France, Germany, Italy, Spain and Japan) markets. The correct numbers for the US market are $\$ 2.6$ billion in 2010 and more than $\$ 5.6$ billion in 2020 (rather than $\$ 3.9$ billion in 2010 and more than $\$ 7.4$ billion in 2020). The error has been corrected in the HTML and PDF versions of the article. 